\title{
Simulation Optimization: Deal or No Deal Using Kelly Strategy
}

\author{
Krunal Patel, Alexandra L. Wang, and Jin Wang
}

\begin{abstract}
Deal or No Deal is a popular television show in many countries around the world over the past years. Along with being interesting show, it is also a suspenseful show. There are many unanswered questions associated with the show for years that yet have not been answered. Such as, how bank decided how much money to offer to contestants? The paper describes Kelly strategy and how the Kelly formula is derived. The comparison is done between Little Monkey strategy who randomly accept or reject the bank's offer and the monkey who uses Kelly formula when making the decision on given bank's offer. The hypothesis is that the average wining amount can be maximized in the long run and beat the Little Monkey strategy. Actual retrieved data set was enough evidence to support the predicted hypothesis. It conclude that Kelly strategy is effective when maximizing the expected winning in long run.
\end{abstract}

Index Terms-System modeling and simulation, kelly strategy, deal or no deal, numerical optimization.

\section{INTRODUCTION}

\section{A. Deal or No Deal}

Deal or No deal is the name relates to popular television show that was originated in Netherlands (See [1]). It was first broadcasted on November 25, 2000 by Dutch producer Endemol. In Dutch it is known as "Miljoenenjacht", which means hunts for millions. It is played with 26 briefcases containing certain sum of money in rage of $\$ 1$ to $\$ 1,000,000$ dollars. The maximum amount of money a player can win is one million dollars in United States version show. This top winning amount may vary depending on different country.

\section{B. Gameplay}

At the beginning of the show, there are twenty six briefcases (suitcases) containing some fixed amount of money shown in Fig. 1. As seen in the Figure 1, the amounts are knowns to both player and bank but neither the player or bank know the exact location of any specific amount.

There are basically nine round through entire game and in each round the player asked to open fix number of cases respectively $6,5,4,3,2,1,1,1$ and 1 . At the end, there are

Manuscript received March 9, 2016; revised June 23, 2016.

K. Patel is with the Department of Computer Science, Valdosta State University, Valdosta, GA 31698 USA (e-mail: kvpatel@valdosta.edu).

A. L. Wang is with the Department of Economics and the Department of Statistics, Harvard University, Cambridge, MA 02138, USA (e-mail: alexandrawang@college.harvard.edu).

J. Wang is with the Department of Mathematics, Valdosta State University, Valdosta, GA 31698 USA (e-mail: jwang@valdosta.edu). two cases remaining and the player have to choose only one that would determine the winning amount. The game begins by the contestant claiming one of the briefcase randomly. The contestant's briefcase value is not revealed until the end of the game or until the contestant accept the bank's offer.

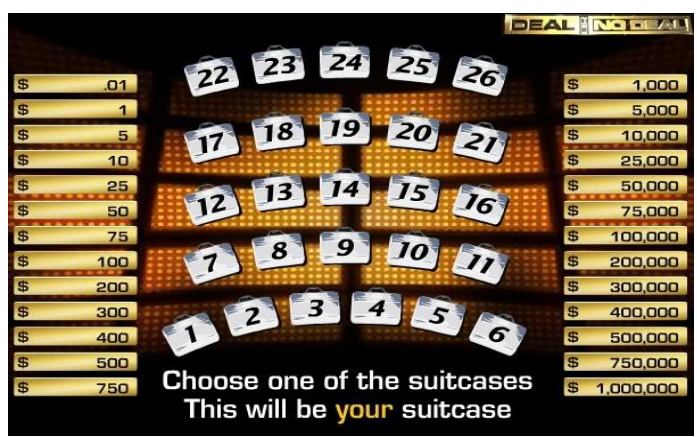

Fig. 1. Note Briefcases and amounts.

Once the contestant select the cases to open they are immediately removed from the game after revealing the amount that particular case contains. Since each case contains a unique amount therefore, the contestant's case does not contain any previously revealed amount. At the end of each round, the bank offer the contestant some amount of money or prize to quit the game. The bank's strategy is to buy the contestant's case for as much as lower price possible than a contestant has chances to win. In reply to bank' offer, the player answers back saying,

"Deal", accept the bank's offer and end the game, or "No Deal", reject the bank's offer and continue playing the game.

This process of opening briefcases at each round and receiving ban's offer continues till either the contestant accept the 'Deal' , or reject all bank's offer until all briefcases' amounts are unveiled.

\section{Implementation}

The research for this project was heavily based on the programming as well as mathematical strategies. The simulator was created using JAVA programming language to be able to play the game and do the numerical analysis over the data retrieved from test runs. The simulator consists of many different classes such as Briefcase, Player, Banker, and Game. The simulator is able to play both player's and bank's role without any conflicts. A large number of tests were ran to achieve accurate results.

\section{BANK'S OFFER}

In Deal or No Deal, bank's offer is interestingly important aspect of the game. Many mathematicians and 
economists have tries to form theories and algorithms that "Bank" uses to calculate the bank offer (See [2]). The bank's offer formula held secret by the various producers around the world. The common assumption is made that the bank even does not know which cases contains what amount. There have been many algorithms formed over the years that have actually came close to the accuracy but yet completely predictable.

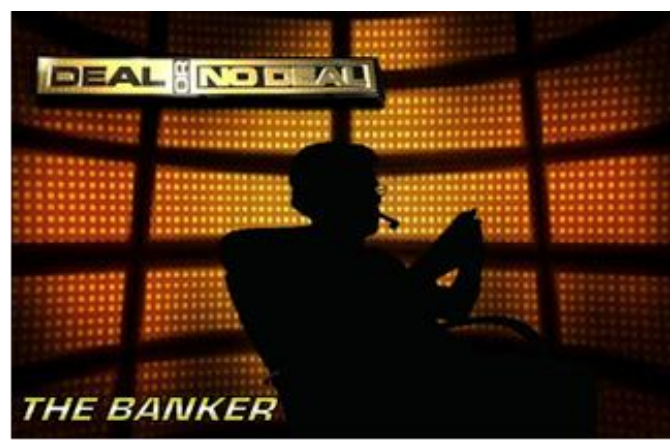

Fig. 2. Banker's mysterious offer.

Some statistical studied linear regression of bank offer versus expected value that a player can win. According to the results, the bank would offer certain percentage of expected winning amount of unopened cases in increased manner from one round to the next one. More precisely, at the first offer this percentage is approximately $40 \%$ of expected value which linearly increase during the game reaching $80 \%$ percent of expected value by seventh offer. For the purpose of this project, a general formula was used to calculate bank's offer in simulator shown in Fig. 3.

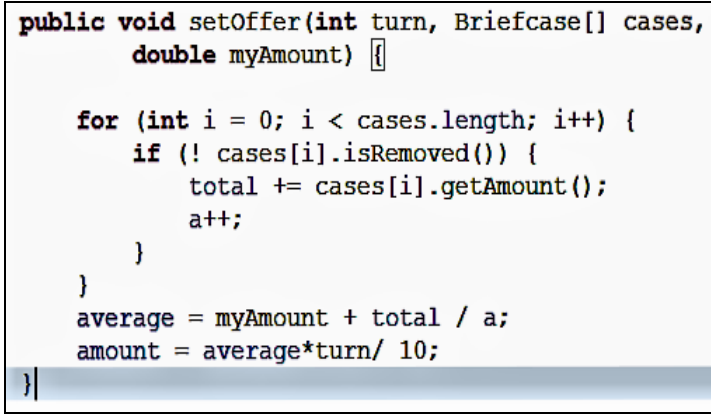

Fig. 3. Banker’s mysterious offer.

Fig. 3 shows that how the simulator calculate the offer after each round. Basically after the player open the predetermined number of boxes in each round, the simulator invokes the method to calculate the offer based on the unopened cases. The method takes an array of cases that are not opened, an integer turn and amount that player case have as inputs. It then goes through the entire list of unopened cases and divided by the number of unopened cases to get average remaining amount. Then if multiply the average remaining amount by the turn number and divide it by 10 that results in a bank's offer.

\section{PlaER's DeCision}

As introduced before, after every bank's offer a player have to make a decision whether to accept the deal or reject the deal. Indeed it is a tough choice to make for any player.
There are real money at stake. The chances of winning or losing depends on how many boxes are unopened. How a player would make the decision? Well, a player either can either randomly makes the decision (Little Monkey) or use some kind of mathematical strategy that provide more informative path to make decision. A player goal should be to maximize the winning amount.

\section{LitTLE MONKEY STRATEGY}

When a player makes a decision on accepting the offer or rejecting the offer, it is a random selection. Neither the player nor the banks can predict if the player will more money the bank or not. For the purpose of this paper, a Little monkey strategy was implemented. A Little monkey strategy is basically randomly choosing to accept or reject the bank's offer. It uses JAVA random generator class to generate random number 0 or 1 . If it is 0 , then the player accept the offer or if it is 1 , then the player reject the offer. The simulator ran one million test run to get accurate average winning amount.

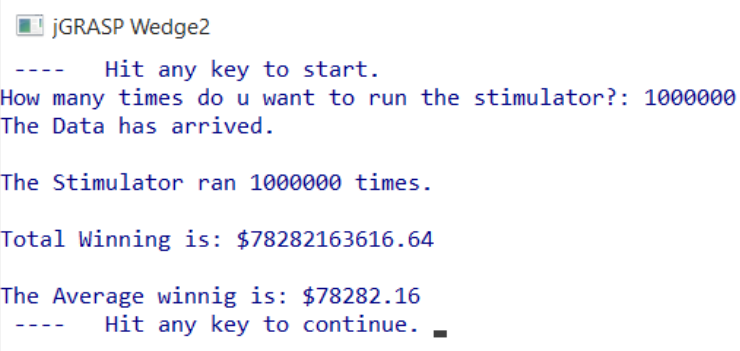

Fig. 4. Little monkey strategy result.

The simulator performed ten tests run and each test run performed the game stimulation a millions times using JGrasp (JAVA Ide). One of the test run result is showed in figure 4, showing that average winning amount using little monkey strategy is approximately $\$ 78,500$. How to optimize average winning amount that can beat little monkey strategy? Kelly strategy may be the option to consider as an answer to our question.

\section{Kelly StRATEGy}

Over the years, Kelly strategy (see [3]-[7], and [8]) is widely accepted into many communities relating to money investment. Kelly strategy also known as Kelly criterion or Kelly formula, is a formula used to decide optimal size of a bet. It was first published by John Kelly, Jr. in 1956 (See [9]). He was a former worker at AT\&T's Bell Laboratory. He developed Kelly Criterion to assist AT\&T with long distance telephone noise issues. After it was published in 1956, soon after the gambling world came to aware of its potential and started using it as an optimal betting system for various betting sports (See [10]). Kelly strategy maximize the size of the bankroll over the long term. Today it is being used by not only gambling community but also in various other fields such as investments, sports, and stock market. Kelly strategy provides better results in a long run but the main disadvantage is that Kelly criterion suggested 
bets may be large. Therefore, it may be risky in short term.

\section{A. Kelly Formula}

There are to major parts of Kelly formula, one is Win probability and other is Win over loss ratio. Putting these two factors into equation returns the Kelly percentage.

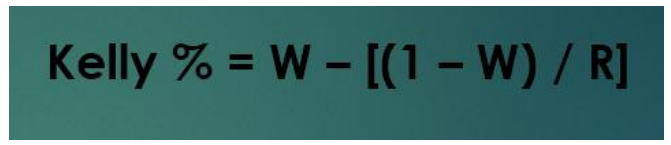

Fig. 5. Kelly formula (Kelly percentage).

As shown in Fig. 5, Kelly equation has two main components $\mathrm{W}$ and $\mathrm{R}$. W is the win probability which is that probability to win higher amount than bank's offer. Where $\mathrm{R}$ is the win over loss ratio, positive win divided by negative win. Kelly equation is bounded from $-\infty$ to 1 but for the purpose of this research, it is bounded from 0 to $1(0$ $<=$ Kelly $\%<1)$.

\section{B. Calculating Win Probability}

Considering the importance of Win probability, calculating win probability accurately is necessary for the Kelly equation. It is the expected value of ration that show what are the odds of winning positive amount.

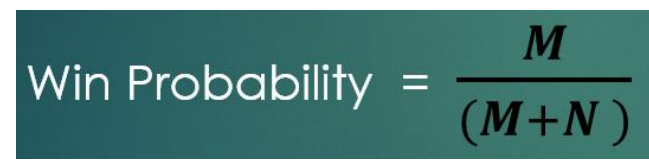

Fig. 6. Win probability calculation.

Two variables $\mathrm{M}$ and $\mathrm{N}$ are defined to calculate win probability. $\mathrm{M}$ is the number of the unopened cases that contains higher amount than the bank's offer. $\mathrm{N}$ is the number of the unopened cases that contains lower amount than the bank's offer. The win probability is calculated by dividing $\mathrm{M}$ by the sum of $\mathrm{M}$ and $\mathrm{N}$ (Fig. 6).

\section{Calculating Win over Loss Ratio}

Winn over Loss ratio $(\mathrm{R})$ is also as important as win probability for Kelly equation. Total positive win amount needs be divided by total lose amount to calculate the ration.

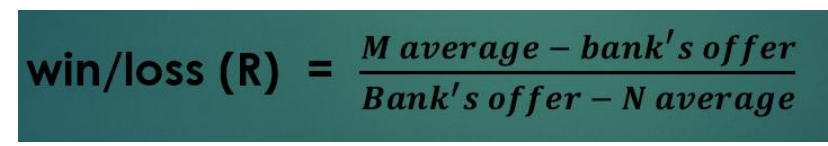

Fig. 7. Win over loss ratio calculation.

Two additional variables are defined to calculate $\mathrm{R}$, the mAverage and nAverage. The mAverage is the average amount of cases that contains higher amount than bank's offer. The nAverage is the average amount of cases that contains lower amount than the bank's offer. First it subtract bank's offer from mAverage and then divide it by sum of bank's offer subtracts nAverage (Fig. 7). Putting W and R in the equation, Kelly equation returns the Kelly percentage.

\section{CRITICAL Point}

It is important to utilize the Kelly percentage correctly into the simulator to get accurate results. As stated before, Kelly percentage returns a number between 0 and 1 . How can it be used to optimize the average winning in the game? It is important to determine that what Kelly percentage result into maximum average winning or beat little monkey strategy. To find out, a critical point is used in simulator. Critical point is used along with the Kelly percentage to decide whether a player should accept the bank's offer or reject it.

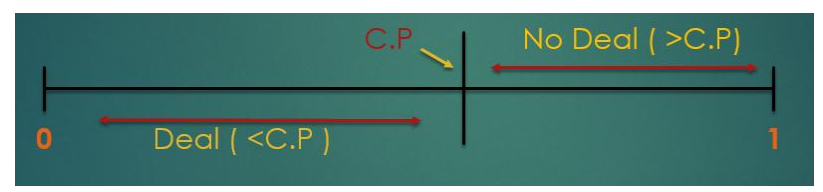

Fig. 8. Critical point and kelly percentage.

As illustrated in Figure 8, if the Kelly percentage is lower than or equal to the critical point that, then the player accept the deal, if Kelly percentage is above the critical point then play simply reject the bank's offer and continue playing the game.

\section{A. Simulation Results}

There are infinite number of points between 0 and 1 . For this project, one hundred critical points were chosen between 0 and 1 such as $0.01,0.02,0.03 \ldots 1.00$.There were 10,000 tests run executed at each critical point totaling of $1,00,000$ tests for accurate results. The results are shown in the graph 1.

As see in Fig. 9, the highest winning amount was approximately $\$ 96,500$ at critical point 0.40 . All the values above grated than 0.40 as critical value beats the little monkey strategy averaging winning amount above $\$ 85,000$. It means that if Kelly percentage is .40 or above, it is safe to accept the bank's offer. It guarantees to beat Little Monkey strategy.

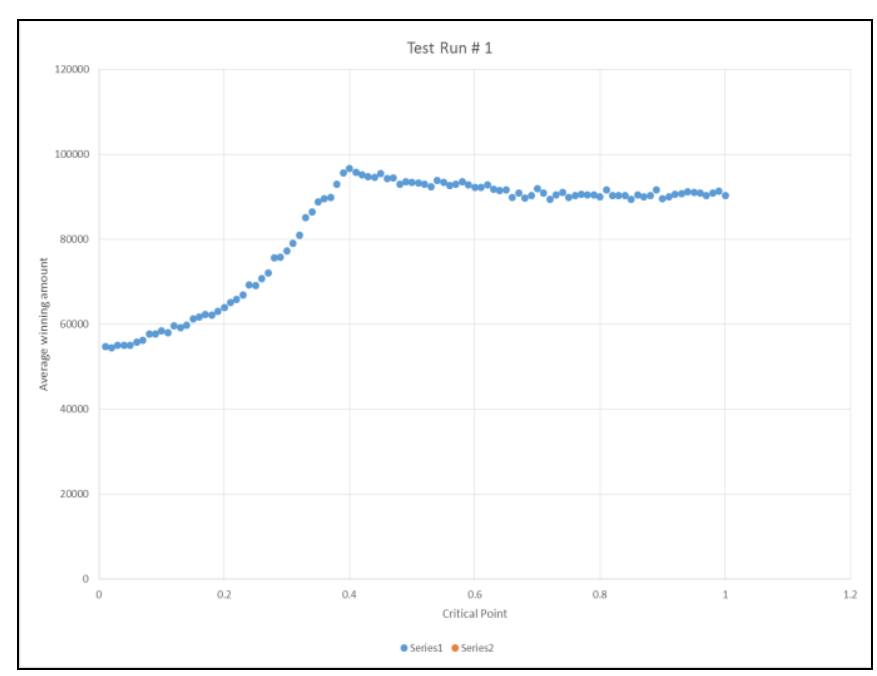

Fig. 4. Kelly Strategy results.

\section{CONCLUSION}

Observing the results from the simulator, it is right to say that Kelly strategy is effective in long run (See [5]). Through the numerical analysis throughout the research, it is possible to optimize the average winning amount in Deal or No Deal game show using Kelly strategy. 


\section{ACKNOWLEDGMENT}

The authors wish to thank all students of the Fall 2015 Operations Research class and faculty members of Department of Math and CS at Valdosta State University for their valuable comments and suggestions. This work was supported in part by the Faculty Research Seed Grant Program from Valdosta State University.

\section{REFERENCES}

[1] Wikipedia. deal or no deal. [Online]. Available: https://en.wikipedia.org/wiki/Deal_or_No_Deal

[2] T. Post, M. J. V. D. Assem, G. Baltussen, and R. H. Thaler, "Deal or no deal? decision making under risk in a large-payoff game show," American Economic Review, vol. 98, No.1, pp. 38-71, 2008.

[3] S. Ethier, "The Kelly system maximizes median fortune," Journal of Applied Probability, vol. 41, no. 4, pp.1230-1236, 2004.

[4] Investopedia. Money management using the Kelly criterion. [Online]. Available: http://www.investopedia.com/articles/trading/04/091504.asp?view=pr int

[5] L. MacLean, E. Thorp, and W. Ziemba, "Long-term capital growth: the good and bad properties of the Kelly and fractional Kelly capital growth criteria," Quantitative Finance, vol. 10, no. 7, 2010.

[6] V. Nekrasov. Kelly criterion for multivariate portfolios: A model-free approach. [Online]. Available: http://ssrn.com/abstract=2259133

[7] E. O. Thorp, "Portfolio choice and the Kelly criterion," in Proc. the Business and Economics Section of the American Statistical Association, pp. 215-224, 1971.
[8] W. T. Ziemba, The Kelly Capital Growth Investment Criterion: Theory and Practice, World Scientific Publishing Company, 2010.

[9] J. Kelly, "A new interpretation of information rate," Bell System Technical Journal, vol. 35, no. 4, pp. 917-926, 1956.

[10] E. O. Thorp, "The Kelly criterion in blackjack, sports betting and the stock market," Handbook of asset and liability management Handbooks in Finance, pp. 385-428, North Holland, 2006.

Krunal Patel is currently a computer science major student at Valdosta State University with a math minor. His research interests include data mining, big data analysis, cloud computing, system modeling and simulation, numerical optimization, financial engineering, and applied statistics.

Alexandra L. Wang is a student at Harvard University studying Economics and Statistics. Her research interests include supply chain management, portfolio optimization, financial engineering, labor economics, law, and applied statistics.

Jin Wang is a professor of mathematics at Valdosta State University. He received his Ph.D. of operations research from the School of Industrial Engineering at Purdue University. His research interests include stochastic modeling and optimization, monte carlo methods, supply chain management, data mining, financial engineering, and applied probability and statistics. 